\title{
Definitions, pathophysiology, and epidemiology of acute cholangitis and cholecystitis: Tokyo Guidelines
}

\author{
Yasutoshi Kimura ${ }^{1}$, Tadahiro Takada 2 , Yoshifumi Kawarada ${ }^{3}$, Yuji Nimura ${ }^{4}$, Koichi Hirata ${ }^{5}$, \\ Mino Sekimoto ${ }^{6}$, Masahiro Yoshida ${ }^{2}$, Toshiniko Mayumi ${ }^{7}$, Keita Wada ${ }^{2}$, Fumihiko Miura ${ }^{2}$, Hideki Yasuda ${ }^{8}$, \\ Yuichi Yamashita ${ }^{9}$, Masato Nagino ${ }^{4}$, Masahiko Hirota ${ }^{10}$, Atsushi Tanaka ${ }^{11}$, Toshio Tsuyuguchi ${ }^{12}$, \\ Steven M. Strasberg ${ }^{13}$, and Thomas R. Gadacz ${ }^{14}$ \\ ${ }^{1}$ First Department of Surgery, Sapporo Medical University School of Medicine, S-1, W-16, Chuo-ku, Sapporo, Hokkaido 060-8543, Japan \\ ${ }^{2}$ Department of Surgery, Teikyo University School of Medicine, Tokyo, Japan \\ ${ }^{3}$ Mie University School of Medicine, Mie, Japan \\ ${ }^{4}$ Division of Surgical Oncology, Department of Surgery, Nagoya University Graduate School of Medicine, Nagoya, Japan \\ ${ }^{5}$ First Department of Surgery, Sapporo Medical University School of Medicine, Sapporo, Japan \\ ${ }^{6}$ Department of Healthcare Economics and Quality Management, Kyoto University Graduate School of Medicine, School of Public Health, \\ Kyoto, Japan \\ ${ }^{7}$ Department of Emergency Medicine and Critical Care, Nagoya University School of Medicine, Nagoya, Japan \\ ${ }^{8}$ Department of Surgery, Teikyo University Chiba Medical Center, Chiba, Japan \\ ${ }^{9}$ Department of Surgery, Fukuoka University Hospital, Fukuoka, Japan \\ ${ }^{10}$ Department of Gastroenterological Surgery, Kumamoto University Graduate School of Medical Science, Kumamoto, Japan \\ ${ }^{11}$ Department of Medicine, Teikyo University School of Medicine, Tokyo, Japan \\ ${ }^{12}$ Department of Medicine and Clinical Oncology, Graduate School of Medicine, Chiba University, Chiba, Japan \\ ${ }^{13}$ Department of Surgery, Washington University in St Louis and Barnes-Jewish Hospital, St Louis, USA \\ ${ }^{14}$ Department of Gastrointestinal Surgery, Medical College of Georgia, Georgia, USA
}

\begin{abstract}
This article discusses the definitions, pathophysiology, and epidemiology of acute cholangitis and cholecystitis. Acute cholangitis and cholecystitis mostly originate from stones in the bile ducts and gallbladder. Acute cholecystitis also has other causes, such as ischemia; chemicals that enter biliary secretions; motility disorders associated with drugs; infections with microorganisms, protozoa, and parasites; collagen disease; and allergic reactions. Acute acalculous cholecystitis is associated with a recent operation, trauma, burns, multisystem organ failure, and parenteral nutrition. Factors associated with the onset of cholelithiasis include obesity, age, and drugs such as oral contraceptives. The reported mortality of less than $10 \%$ for acute cholecystitis gives an impression that it is not a fatal disease, except for the elderly and/or patients with acalculous disease. However, there are reports of high mortality for cholangitis, although the mortality differs greatly depending on the year of the report and the severity of the disease. Even reports published in and after the 1980s indicate high mortality, ranging from $10 \%$ to $30 \%$ in the patients, with multiorgan failure as a major cause of death. Because many of the reports on acute cholecystitis and cholangitis use different standards, comparisons are difficult. Variations in treatment and risk factors influencing the mortality rates indicate the necessity for standardized diagnostic, treatment, and severity assessment criteria.
\end{abstract}

Offprint requests to: Y. Kimura

Received: May 31, 2006 / Accepted: August 6, 2006
Key words Gallstones - Biliary - Bile - Biliary infection · Cholangitis · Acute cholecystitis · Guidelines

\section{Introduction}

Acute biliary infection is a systemic infectious disease which requires prompt treatment and has a significant mortality rate. ${ }^{1}$ The first report on acute biliary infection was Charcot's "The symptoms of hepatic fever" in $1877 .^{2}$

This section of the Tokyo Guidelines defines acute cholangitis and acute cholecystitis, and describes the incidence, etiology, pathophysiology, classification, and prognosis of these diseases.

\section{Acute cholangitis}

\section{Definition}

Acute cholangitis is a morbid condition with acute inflammation and infection in the bile duct.

\section{Historical aspects of terminology}

Hepatic fever. "Hepatic fever" was a term used for the first time by Charcot, ${ }^{2}$ in his report published in 1877. Intermittent fever accompanied by chills, right upper quadrant pain, and jaundice became known as Charcot's triad. 
Acute obstructive cholangitis. Acute obstructive cholangitis was defined by Reynolds and Dargan ${ }^{3}$ in 1959 as a syndrome consisting of lethargy or mental confusion and shock, as well as fever, jaundice, and abdominal pain, caused by biliary obstruction. They indicated that emergent surgical biliary decompression was the only effective procedure for treating the disease. These five symptoms were then called Reynolds's pentad.

Longmire's classification. ${ }^{4}$ Longmire classified patients with the three characteristics of intermittent fever accompanied by chills and shivering, right upper quadrant pain, and jaundice as having acute suppurative cholangitis. Patients with lethargy or mental confusion and shock, along with the triad, were classified as having acute obstructive suppurative cholangitis (AOSC). He also reported that the latter corresponded to the morbidity of acute obstructive cholangitis as defined by Reynolds and Dargan, ${ }^{3}$ and he classified acute microbial cholangitis as follows:

1. Acute cholangitis developing from acute cholecystitis

2. Acute non-suppurative cholangitis

3. Acute suppurative cholangitis

4. Acute obstructive suppurative cholangitis

5. Acute suppurative cholangitis accompanied by hepatic abscess.

\section{Incidence}

\section{Etiology}

Acute cholangitis requires the presence of two factors: (1) biliary obstruction and (2) bacterial growth in bile (bile infection). Frequent causes of biliary obstruction are choledocholithiasis, benign biliary stenosis, stricture of a biliary anastomosis, and stenosis caused by malignant disease (level 4). ${ }^{5,6}$ Choledocholithiasis used to be the most frequent cause of the obstruction, but recently, the incidence of acute cholangitis caused by malignant disease, sclerosing cholangitis, and non-surgical instrumentation of the biliary tract has been increasing. It is reported that malignant disease accounts for about $10 \%-30 \%$ of cases of acute cholangitis. Tables 1 and 2 show some results of studies on the causes of acute cholangitis.

Risk factors. The bile of healthy subjects is generally aseptic. However, bile culture is positive for microorganisms in $16 \%$ of patients undergoing a non-biliary operation, in $72 \%$ of acute cholangitis patients, in $44 \%$ of chronic cholangitis patients, and in $50 \%$ of those with biliary obstruction (level 4$).{ }^{12}$ Bacteria in bile are identified in $90 \%$ of patients with choledocholithiasis accompanied by jaundice (level 4) ${ }^{13}$ Patients with incomplete

Table 1. Etiology of acute cholangitis

Cholelithiasis

Benign biliary stricture

Congenital factors

Postoperative factors (damaged bile duct, strictured

choledojejunostomy, etc.)

Inflammatory factors (oriental cholangitis, etc.)

Malignant occlusion

Bile duct tumor

Gallbladder tumor

Ampullary tumor

Pancreatic tumor

Duodenal tumor

Pancreatitis

Entry of parasites into the bile ducts

External pressure

Fibrosis of the papilla

Duodenal diverticulum

Blood clot

Sump syndrome after biliary enteric anastomosis

Iatrogenic factors

Table 2. Causes of acute cholangitis (\%)

\begin{tabular}{|c|c|c|c|c|c|c|c|c|}
\hline \multirow[b]{2}{*}{ Author } & \multirow[b]{2}{*}{ Year } & \multirow[b]{2}{*}{ Setting } & \multirow[b]{2}{*}{$N$} & \multicolumn{5}{|c|}{ Causes } \\
\hline & & & & $\begin{array}{c}\text { GB } \\
\text { stones }\end{array}$ & $\begin{array}{l}\text { Benign } \\
\text { stenosis }\end{array}$ & $\begin{array}{l}\text { Malignant } \\
\text { stenosis }\end{array}$ & $\begin{array}{l}\text { Sclerosing } \\
\text { cholangitis }\end{array}$ & $\begin{array}{l}\text { Others/ } \\
\text { unknown }\end{array}$ \\
\hline Gigot $^{6}$ & 1963-1983 & University of Paris & 412 & $48 \%$ & $28 \%$ & $11 \%$ & $1.5 \%$ & - \\
\hline Saharia and Cameron ${ }^{7}$ & $1952-1974$ & $\begin{array}{l}\text { Johns Hopkins } \\
\text { Hospital, USA }\end{array}$ & 76 & $70 \%$ & $13 \%$ & $17 \%$ & $0 \%$ & - \\
\hline Pitt and Couse ${ }^{8}$ & 1976-1978 & $\begin{array}{l}\text { Johns Hopkins } \\
\text { Hospital, USA }\end{array}$ & 40 & $70 \%$ & $18 \%$ & $10 \%$ & $3 \%$ & - \\
\hline Pitt and Couse ${ }^{8}$ & 1983-1985 & $\begin{array}{l}\text { Johns Hopkins } \\
\text { Hospital, USA }\end{array}$ & 48 & $32 \%$ & $14 \%$ & $30 \%$ & $24 \%$ & - \\
\hline Thompson $^{9}$ & 1986-1989 & $\begin{array}{l}\text { Johns Hopkins } \\
\text { Hospital, USA }\end{array}$ & 96 & $28 \%$ & $12 \%$ & $57 \%$ & $3 \%$ & - \\
\hline Basoli $^{10}$ & 1960-1985 & University of Rome & 80 & $69 \%$ & $16 \%$ & $13 \%$ & $0 \%$ & $4 \%$ \\
\hline Daida $^{11}$ & 1979 & $\begin{array}{l}\text { Questionnaire throughout } \\
\text { Japan }\end{array}$ & 472 & $56 \%$ & $5 \%$ & $36 \%$ & - & $3 \%$ \\
\hline
\end{tabular}


obstruction of the bile duct present a higher positive bile culture rate than those with complete obstruction of the bile duct. Risk factors for bactobilia include various factors, as described above. ${ }^{14}$

Post-endoscopic retrograde cholangiopancreatography $(E R C P)$ infectious complications. The incidence of complications after ERCP ranges from $0.8 \%$ to $12.1 \%$, though it differs depending on the year of the report and the definition of complications (level 4). ${ }^{15-23}$ Overall post-ERCP mortality is reported to be between $0.5 \%$ and $1.5 \%$ (level 4). ${ }^{18}$ The most frequent complication is acute pancreatitis, but it is usually mild or moderate. Table 3 shows the reported incidence of various postERCP complications.

The incidences of post-ERCP acute cholangitis and cholecystitis are, as shown in Table 3, $0.5 \%-1.7 \%$ and $0.2 \%-0.5 \%$, respectively. ${ }^{15-19}$ The complications caused by ERCP performed for diagnostic and for therapeutic purposes are different. Therapeutic ERCP tends to cause all complications, including cholangitis, more frequently than diagnostic ERCP. ${ }^{17,20}$

The increasing use of ERCP and the improved operators' skills and techniques in recent years have reduced the incidence of post-ERCP complications, although the incidence of acute cholecystitis has not dropped and seems unpredictable. ${ }^{17}$

Other etiologies of acute cholangitis. There are two other etiologies of acute cholangitis; Mirizzi syndrome and lemmel syndrome. Mirizzi syndrome is a morbid condition with stenosis of the common bile duct caused by mechanical pressure and/or inflammatory changes caused by the presence of stones in the gallbladder neck and cystic ducts. ${ }^{24}$ Two types have been described: type $I$, which is a morbid condition with the bile duct compressed from the left by the presence of stones in the gallbladder neck and cystic ducts and pericholecystic inflammatory changes; and type II, which is a morbid condition with biliobilary fistulation caused by pressure necrosis of the bile duct due to cholecystolithiasis.

Lemmel syndrome is a series of morbid conditions in which the duodenal parapapillary diverticulum compresses or displaces the opening of the bile duct or pancreatic duct and obstructs the passage of bile in the bile duct or hepatic duct, thereby causing cholestasis, jaundice, gallstone, cholangitis, and pancreatitis. ${ }^{25}$

\section{Pathophysiology}

The onset of acute cholangitis involves two factors: (i) increased bacteria in the bile duct, and (ii) elevated intraductal pressure in the bile duct that allows translocation of bacteria or endotoxins into the vascular system (cholangio-venous reflux). Because of its anatomical characteristics, the biliary system is likely to be affected by elevated intraductal pressure. In acute cholangitis, with the elevated intraductal biliary pressure, the bile ductules tend to become more permeable to the translocation of bacteria and toxins. This process results in serious infections that can be fatal, such as hepatic abscess and sepsis.

\section{Prognosis}

Patients who show early signs of multiple organ failure (renal failure, disseminated intravascular coagulation [DIC], alterations in the level of consciousness, and shock) as well as evidence of acute cholangitis (fever accompanied by chills and shivering, jaundice, and abdominal pain), and who do not respond to conservative treatment, should receive systemic antibiotics and undergo emergent biliary drainage. ${ }^{1}$ We have to keep in mind that unless early and appropriate biliary drainage is performed and systemic antibiotics are administered, death will occur.

The reported mortality of acute cholangitis varies from $2.5 \%$ to $65 \%{ }^{26-37}$ (Table 4 ). The mortality rate before 1980 was $50 \%,{ }^{26,27}$ and after 1980 it was $10 \%-$ $30 \% .^{28-37}$ Such differences in mortality are probably attributable to differences in early diagnosis and improved supportive treatment.

The major cause of death in acute cholangitis is multiple organ failure with irreversible shock, and mortality rates have not significantly improved over the years. ${ }^{26-33}$ Causes of death in patients who survive the acute stage of cholangitis include multiple organ failure, heart failure, and pneumonia. ${ }^{34}$

\section{Acute cholecystitis}

\section{Definition}

Acute cholecystitis is an acute inflammatory disease of the gallbladder. It is often attributable to gallstones, but many factors, such as ischemia; motility disorders; direct chemical injury; infections with microorganisms, protozoa, and parasites; collagen disease; and allergic reaction are involved.

\section{Incidence}

Acute cholecystitis cases account for $3 \%-10 \%$ of all patients with abdominal pain. ${ }^{38-40}$ The percentage of acute cholecystitis cases in patients under 50 years old with abdominal pain $(n=6317)$ was low, at $6.3 \%$, whereas that in patients aged 50 and over $(n=2406)$ was high, at $20.9 \%$ (average, $10 \%)^{40}$ (Table 5).

\section{Etiology}

Cholecystolithiasis accounts for $90 \%-95 \%$ of all causes of acute cholecystitis, while acalculous cholecystitis accounts for the remaining 5\%-10\% (level 4). ${ }^{41-47}$ 


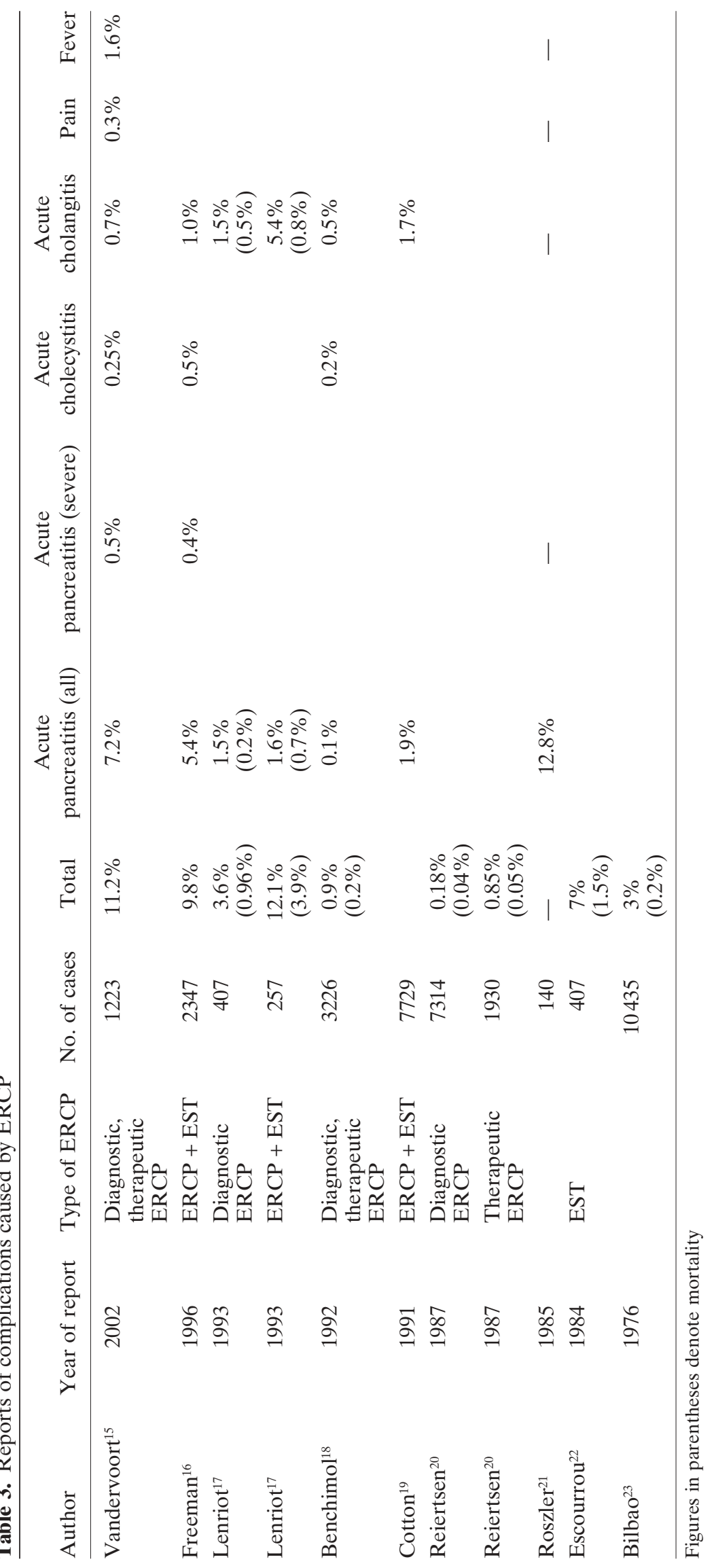


Table 4. Mortality of acute cholangitis

\begin{tabular}{lclcc}
\hline Author & Period & Country & No. of subjects & Mortality (\%) \\
\hline Andrew $^{26}$ & $1957-1967$ & USA & $17^{\mathrm{c}}$ & 64.71 \\
Shimada $^{27}$ & $1975-1981$ & Japan & $42^{\mathrm{b}}$ & 57.1 \\
Csendes $^{28}$ & $1980-1988$ & Chile & 512 & 11.91 \\
Himal and Lindsac $^{29}$ & $1980-1989$ & Canada & 61 & 18.03 \\
Chijiiwa $^{30}$ & $1980-1993$ & Japan & $27^{\mathrm{c}}$ & 11.11 \\
Liu $^{31}$ & $1982-1987$ & Taiwan & $47^{\mathrm{a}}$ & 27.66 \\
Lai $^{32}$ & $1984-1988$ & Hong Kong & $86^{\mathrm{b}}$ & 19.77 \\
Thompson $^{33}$ & $1984-1988$ & USA & 127 & 3.94 \\
Arima $^{34}$ & $1984-1992$ & Japan & 163 & 2.45 \\
Kunisaki $^{35}$ & $1984-1994$ & Japan & 82 & 10.98 \\
Tai $^{36}$ & $1986-1987$ & Taiwan & 225 & 6.67 \\
Thompson $^{37}$ & $1986-1989$ & USA & 96 & 5.21 \\
\hline
\end{tabular}

anly patients with shock

${ }^{\mathrm{b}}$ Only severe cases

${ }^{\mathrm{c}}$ Only AOSC

Table 5. Acute cholecystitis in patients with abdominal pain

\begin{tabular}{|c|c|c|c|c|c|c|c|}
\hline \multicolumn{8}{|c|}{ Reports of all patients with abdominal pain } \\
\hline \multirow{2}{*}{\multicolumn{2}{|c|}{$\begin{array}{c}\text { Eskelinen et al. }{ }^{38} \\
\quad n=1333\end{array}$}} & \multirow{2}{*}{\multicolumn{2}{|c|}{$\begin{array}{l}\text { Brewer et al. }{ }^{39} \\
\quad n=1000\end{array}$}} & \multicolumn{4}{|c|}{ Telfer ${ }^{40}$} \\
\hline & & & & \multicolumn{2}{|c|}{$\begin{array}{c}\text { Under } 50 \\
\text { years old }(n=6317)\end{array}$} & \multicolumn{2}{|c|}{$\begin{array}{c}50 \text { years and } \\
\text { over }(n=2406)\end{array}$} \\
\hline $\begin{array}{l}\text { Nonspecific } \\
\text { abdominal pain }\end{array}$ & 618 & Unknown cause & 413 & $\begin{array}{l}\text { Nonspecific } \\
\text { abdominal pain }\end{array}$ & $39.5 \%$ & Acute cholecystitis & $20.9 \%$ \\
\hline Appendicitis & 271 & Gastroenteritis & 69 & Appendicitis & $32.0 \%$ & $\begin{array}{l}\text { Nonspecific } \\
\text { abdominal pain }\end{array}$ & $15.7 \%$ \\
\hline Acute cholecystitis & 124 & $\begin{array}{l}\text { Intrapelvic } \\
\text { infection }\end{array}$ & 67 & Acute cholecystitis & $6.3 \%$ & Appendicitis & $15.2 \%$ \\
\hline Ileus & 53 & $\begin{array}{l}\text { Urinary tract } \\
\text { infection }\end{array}$ & 52 & Ileus & $2.5 \%$ & Ileus & $12.3 \%$ \\
\hline Dyspepsia & 50 & Ureterolith & 43 & Acute hepatitis & $1.6 \%$ & Acute hepatitis & $7.3 \%$ \\
\hline Ureterolith & 57 & Appendicitis & 43 & Diverticulitis & $<0.1 \%$ & Diverticulitis & $5.5 \%$ \\
\hline Diverticulitis & 19 & Acute cholecystitis & 25 & Cancer & $<0.1 \%$ & Cancer & $4.1 \%$ \\
\hline $\begin{array}{l}\text { Mesenteric } \\
\text { lymphadenitis }\end{array}$ & 11 & Ileus & 25 & Hernia & $<0.1 \%$ & Hernia & $3.1 \%$ \\
\hline Acute pancreatitis & 22 & Constipation & 23 & Vascular lesion & $<0.1 \%$ & Vascular lesion & $2.3 \%$ \\
\hline $\begin{array}{l}\text { Peptic ulcer } \\
\text { perforation }\end{array}$ & 9 & Duodenal ulcer & 20 & & & & \\
\hline $\begin{array}{l}\text { Urinary tract } \\
\text { infection }\end{array}$ & 22 & Dysmenorrhea & 18 & & & & \\
\hline $\begin{array}{l}\text { Gynecological } \\
\text { diseases }\end{array}$ & 15 & Pregnancy & 18 & & & & \\
\hline \multirow[t]{5}{*}{ Others } & 62 & Pyelitis & 17 & & & & \\
\hline & & Gastritis & 14 & & & & \\
\hline & & $\begin{array}{l}\text { Chronic } \\
\text { cholecystitis }\end{array}$ & 12 & & & & \\
\hline & & Ovarian abscess & 10 & & & & \\
\hline & & Dyspepsia & 10 & & & & \\
\hline
\end{tabular}

Risk factors. Acute cholecystitis is the most frequent complication occurring in patients with cholelithiasis. According to the Comprehensive Survey of Living Conditions of the People on Health and Welfare conducted by the Medical Statistics Bureau of the Japanese Ministry of Health and Welfare, the number of those with acute cholecystitis has increased, from 3.9 million in 1979 to over 10 million in 1993 (Public Welfare Index in Japan; 1933; level 4).

According to the review by Friedman, ${ }^{48}$ of the natural history of cholelithiasis, serious symptoms or complications (acute cholecystitis, acute cholangitis, clinical 
jaundice, and pancreatitis) were observed in $1 \%-2 \%$ of asymptomatic patients and in $1 \%-3 \%$ of patients with mild symptoms per year (Table 6), and the risk of complications increased in the first several years after the discovery of gallbladder stones, but then decreased (level 2c). Every year, $6 \%-8 \%$ of patients whose symptoms progress from minor to serious undergo cholecystectomy, but this percentage decreases year by year. ${ }^{48}$

In a follow-up of cholelithiasis patients with mild or nonspecific symptoms $(n=153)$, acute gallstone complication was observed in $15 \%(n=23)$ and acute cholecystitis was seen in $12 \%(n=18)$ (level 4$){ }^{49}$ According to another report, on the follow-up of the patients with asymptomatic cholelithiasis $(n=600), 16 \%(96)$ of them presented with some symptoms (average period of observation until the manifestation of symptom, 29.8 months) during the follow-up period, while 3.8\% (23 patients) presented with acute cholecystitis. The rate of change from asymptomatic to symptomatic cholelithiasis is highest during the first 3 years after diagnosis $(15 \%-26 \%)$, but then declines (level 4). However, there is a report suggesting that there is no difference in the incidence of common symptoms such as heartburn and upper abdominal pain, in cholelithiasis patients between those patients with asymptomatic cholelithiasis and controls without gallstones (level 2b)..$^{50}$

AIDS as a risk factor. Enlarged liver and/or abnormal liver functions are observed in two/thirds of AIDS patients, some of whom have biliary tract disease. Biliary disease may occur by two mechanisms in AIDS patients: via AIDS cholangiopathy (which is more fre- quent) and via acute acalculous cholecystitis; AIDS patients with sclerosing cholangitis are also seen.

AIDS cholangiopathy is often observed in middleaged male patients who have had AIDS for more than 1 year (average disease period, $15 \pm 2.2$ months; average age, 37 years [range, 21 to 59 years]). Ninety percent of the patients complain of upper abdominal pain and have enlarged intra- and extrahepatic bile ducts on abdominal ultrasonography. Abnormal findings on abdominal ultrasonography and computed tomography are seen in $81 \%$ and $78 \%$ of patients, respectively. Biochemical tests show a marked increase in the level of alkaline phosphatase (level 4). ${ }^{51}$

Acalculous cholecystitis in AIDS patients is characterized by: (1) younger age than in non-AIDS patients, (2) problems with oral ingestion (3), right upper abdominal pain, (4) a marked increase in alkaline phosphatase and a mild increase in serum bilirubin level, and (5) association with cytomegalovirus and cryptosporidium infections (level 4).$^{51}$ According to a review of abdominal surgery for AIDS patients, acute cholecystitis is the most frequent reason for performing open surgery in AIDS patients. ${ }^{52}$

Drugs as etiologic agents. According to the review by Michielsen et al., ${ }^{53}$ regarding the association between drugs and acute cholecystitis, $90 \%-95 \%$ of acute cholecystitis cases are caused by cholelithiasis, and drugs promoting the formation of stones are indirectly associated with a risk of acute cholecystitis (level 4). The etiological mechanism of drug-associated gallbladder diseases, as discussed in the review, ${ }^{53}$ is shown in Table 7.

Table 6. Natural history of asymptomatic, mildly symptomatic, and symptomatic cholelithiasis patients

\begin{tabular}{|c|c|c|c|c|c|c|c|c|}
\hline Author & Characteristic & $\begin{array}{l}\text { No. of } \\
\text { cases }\end{array}$ & $\begin{array}{l}\text { Average } \\
\text { follow-up } \\
\text { period } \\
\text { (years) }\end{array}$ & $\begin{array}{l}\text { No. of acute } \\
\text { cholecystitis } \\
\text { cases }(\%)\end{array}$ & $\begin{array}{l}\text { Only those with } \\
\text { remarkable } \\
\text { jaundice } \\
(\%)\end{array}$ & Cholangitis & Cholecystitis & $\begin{array}{c}\text { Gallbladder } \\
\text { cancer }\end{array}$ \\
\hline Comfort et al. & Asymptomatic & 112 & 15 & 0 & 0 & 0 & 0 & 0 \\
\hline Lund & Asymptomatic & 95 & 13 & $?$ & $?$ & $1(?)$ & 0 & 0 \\
\hline Gracie et al. & Asymptomatic & 123 & 11 & 2 & 0 & 0 & 1 & 0 \\
\hline McSherry et al. & Asymptomatic & 135 & 5 & 3 & 0 & 0 & 0 & 0 \\
\hline Friedman et al. & Asymptomatic & 123 & 7 & 4 & 2 & 2 & 0 & 0 \\
\hline Thistle et al. & $\begin{array}{l}\text { Asymptomatic } \\
\text { + Symptomatic }\end{array}$ & 305 & 2 & $\geq 3$ & 0 & 0 & 0 & 0 \\
\hline Wenckert et al. & $\begin{array}{l}\text { Mildly } \\
\text { symptomatic }\end{array}$ & 781 & 11 & $81(10.4)$ & $<59^{a}$ & 0 & $<59^{a}$ & 3 \\
\hline Ralston et al. & $\begin{array}{l}\text { Mildly } \\
\text { symptomatic }\end{array}$ & 116 & 22 & $?$ & $?$ & $?$ & $?$ & 2 \\
\hline Friedman et al. & $\begin{array}{l}\text { Mildly } \\
\text { symptomatic }\end{array}$ & 344 & 9 & $20(5.8)$ & 10 & 1 & 3 & 2 \\
\hline Newman et al. & Symptomatic & 332 & 10 & 38 (11.4) & $?$ & $?$ & 1 & 2 \\
\hline McSherry et al. & Symptomatic & 556 & 7 & $47(8.5)$ & 19 & 0 & 0 & 1 \\
\hline
\end{tabular}

Review by Friedman ${ }^{48}$

${ }^{a}$ In this report, 59 cases were diagnosed as jaundice and/or acute pancreatitis, based on serum bilirubin and amylase values 
Table 7. Etiological mechanisms of gallbladder diseases

\begin{tabular}{|c|c|}
\hline Etiological mechanism & Drug/Treatment \\
\hline Direct chemical toxicity & Hepatic artery infusion \\
\hline \multicolumn{2}{|l|}{ Promotion of stone formation by bile } \\
\hline Inhibition of ACAT activity & Progesterone, fibrate \\
\hline Increased hepatic lipoprotein receptors & Estrogen \\
\hline $\begin{array}{l}\text { Induction of acute cholecystitis in patients } \\
\text { with cholelithiasis }\end{array}$ & Thiazides (unconfirmed) \\
\hline Promotion of calcium salt precipitation in bile & Ceftriaxone octreotide \\
\hline \multirow[t]{2}{*}{ Altered mobility of the gallbladder } & Narcoid \\
\hline & Anticholinergic drugs \\
\hline Promotion of hemolysis & Dapsone \\
\hline \multirow[t]{2}{*}{ Immunological mechanism } & $\begin{array}{l}\text { Antimicrobial drugs (erythromycin, } \\
\text { ampicillin) }\end{array}$ \\
\hline & Immunotherapy \\
\hline
\end{tabular}

Review by Michielsen et al..$^{53}$

It is reported that women taking oral conceptives have a higher risk of having gallbladder disease, but there also is a report which denies the association between the disease and these drugs (level 2a). ${ }^{54}$ Among various drugs used for the treatment of hyperlipidemia, only fibrate is shown to be associated with gallstone diseases (level 2b). ${ }^{55}$ One report suggests that thiazides induce acute cholecystitis (level 3b), ${ }^{56}$ and another report denies this association (level 3b). ${ }^{57}$ The administration of a large dose of ceftriaxone, a third-generation cephalosporin antimicrobial, in infants, precipitates calcium salt in bile and forms a sludge in $25 \%-45 \%$ of them, but these effects disappear when the medication is discontinued (level 4). ${ }^{53}$ It is reported that the longterm administration of octreotide causes cholestasis, and that administration for a year causes cholelithiasis in $50 \%$ of patients (level 4). ${ }^{53}$ Hepatic artery infusion will cause chemical cholecystitis (level 4). ${ }^{53}$ Erythromycin and ampicillin are reported to be a cause of hypersensitive cholecystitis (level 4). ${ }^{53}$ According to a meta-analysis of the risk of disease induced by hormone replacement therapy, the relative risks (RRs) of cholecystitis were 1.8 (95\% confidence interval [CI], 1.6-2.0) and 2.5 (95\% CI, 2.0-2.9) at less than 5 years of treatment and at 5 and more years, respectively (level 1a). ${ }^{58}$

Ascaris as an etiologic factor. The complications of ascariasis include hepatic, biliary, and pancreatic diseases. Complications in the biliary tract include: (1) cholelithiasis with the ascarid as a nidus for stone formation, (2) acalculous cholecystitis (3), acute cholangitis (4), acute pancreatitis, and (5) hepatic abscess. ${ }^{59}$ Biliary tract disease is caused by the obstruction of the hepatic and biliary tracts by the entry of ascarids from the duodenum through the papilla. Ascarids entering the biliary tract usually return to the duodenum in a week, but if they stay over 10 days there, they will die and form a nidus for stone formation.

Ascarid-associated biliary diseases occur more frequently in women (male/female ratio, 1:3) and less frequently in infants. The risk of biliary complications is higher in pregnant than in non-pregnant women (level 4). ${ }^{59}$ In epidemic regions such as China and Southeast Asia, ascariasis is a frequent cause of cholelithiasis. ${ }^{59}$

Role of pregnancy. The risk of cholelithiasis in women begins to increase when adolescence begins and it declines when the menopause begins. It is also said that the use of oral conceptives is correlated with a risk of gallbladder disease. It is considered, therefore, that levels of estrogen and progesterone are involved in the formation of gallstones. ${ }^{60}$ Cholecystitis is the second most common cause of acute abdomen, following appendicitis, in pregnant women, and occurs in one of 1600 to 10000 pregnant women (level 4). ${ }^{60}$ Cholelithiasis is the most frequent cause of cholecystitis in pregnancy and accounts for $90 \%$ or more of all causes of cholecystitis (level 4). ${ }^{60}$ Routine ultrasonography found cholelithiasis in $3.5 \%$ of pregnant women (level 4$),{ }^{60}$ but it is unknown whether pregnancy increases the risk of cholecystitis. The frequency of cholecystectomy in pregnant women is lower than that in non-pregnant women. This is not because of the lower incidence of cholecystectomy in pregnant women, but because physicians tend to refrain from performing any operation during pregnancy. Though there are few reports of patients undergoing cholecystectomy during pregnancy, there is no evidence that laparoscopic surgery increases the maternal or fetal risks (level 2c). ${ }^{61}$

Acute cholecystitis and four (or five) " $F s$ ". It has been said that the patients with cholelithiasis have factors such as "4F" and " $5 F$ " (fair, fat, female, fertile, and 
forty). Common to all individuals with these " $4 / 5 \mathrm{Fs}$ " are high levels of estrogen and progesterone.

According to the Framingham Study, which examined the risk factors for cholelithiasis in a 10-year follow-up study of 30- to 59-year-old subjects, the risk of cholelithiasis within 10 years was highest among the 55- to 62-year-old age group, and most of the patients were diagnosed with cholelithiasis in their fifties and sixties. Although the incidence of cholelithiasis in female patients of all age groups is more than double that of male patients, the difference between the incidence in men and women tends to shrink with increasing age (level 1b). ${ }^{62}$

Cholelithiasis is one of the main diseases associated with obesity. The Framingham study also confirms that cholelithiasis patients tend to be more obese than noncholelithiasis patients (level 2a). ${ }^{62}$ However, there is a report that this tendency is much more prominent in female than in male patients. ${ }^{63}$ Not only obesity but also dieting is associated with the risk of cholelithiasis. Drastic dieting increases the risk of cholelithiasis in obese people (level 2b). ${ }^{64-67}$ The incidences of both cholelithiasis and cholecystitis in obese people (age, 37-60 years; women with a body mass index [BMI] of 34 or higher and men with a BMI of 38 or more) are significantly higher that those in non-obese people (cholelithiasis, $5.8 \%$ vs $1.5 \%$; Odds ratio [OR], 4.9; women $6.4 \%$ vs $22.6 \%$; OR, 4.7; cholecystitis, $0.8 \%$ vs $3.4 \%$; OR, 5.2; women $4.0 \%$ vs $11.2 \%$; OR, 3.4) (level 2b). ${ }^{68}$

The Framingham Study indicates that the number of pregnancies in those patients who had cholelithiasis at entry into a cohort or those in whom the symptoms of cholelithiasis appeared within 10 years, was significantly higher than the number of pregnancies in subjects not fulfilling these criteria (level 2b). ${ }^{62}$

Though the association of " $4 \mathrm{~F}$ " and " $5 \mathrm{~F}$ " with cholelithiasis has been relatively closely examined, no study has examined the association of factors other than obesity and age with the risk of onset of acute cholecystitis.

\section{Pathophysiology}

In the majority of patients, gallstones are the cause of acute cholecystitis. The process is one of physical obstruction of the gallbladder by a gallstone, at the neck or in the cystic duct. This obstruction results in increased pressure in the gallbladder. There are two factors which determine the progression to acute cholecystitis - the degree of obstruction and the duration of the obstruction. If the obstruction is partial and of short duration the patient experiences biliary colic. If the obstruction is complete and of long duration the patient develops acute cholecystitis. If the patient does not receive early treatment, the disease becomes more serious and complications occur.

\section{Pathological classification}

Edematous cholecystitis: first stage (2-4 days). The gallbladder has interstitial fluid with dilated capillaries and lymphatics. The gallbladder wall is edematous. The gallbladder tissue is intact histologically, with edema in the subserosal layer.

Necrotizing cholecystitis: second stage (3-5 days). The gallbladder has edematous changes with areas of hemorrhage and necrosis. When the gallbladder wall is subjected to elevated internal pressure, the blood flow is obstructed, with histological evidence of vascular thrombosis and occlusion. There are areas of scattered necrosis, but it is superficial and does not involve the full thickness of the gallbladder wall.

Suppurative cholecystitis: third stage (7-10 days). The gallbladder wall has white blood cells present, with areas of necrosis and suppuration. In this stage, the active repair process of inflammation is evident. The enlarged gallbladder begins to contract and the wall is thickened due to fibrous proliferation. Intrawall abscesses are present and involve the entire thickness of the wall. Pericholecystic abscesses are present.

Chronic cholecystitis. Chronic cholecystitis occurs after the repeated occurrence of mild attacks of cholecystitis, and is characterized by mucosal atrophy and fibrosis of the gallbladder wall. It can also be caused by chronic irritation by large gallstones and may often induce acute cholecystitis.

Specific forms of acute cholecystitis. There are four specific forms of acute cholecystitis: (1) acalculous cholecystitis, which is acute cholecystitis without cholecystolithiasis; (2) xanthogranulomatous cholecystitis, which is characterized by the xanthogranulomatous thickening of the gallbladder wall and elevated intra-gallbladder pressure due to stones, with rupture of the the Rokitansky-Achoff sinuses. This rupture causes leakage and bile entry into the gallbladder wall. The bile is ingested by histocytes, forming granulomas consisting of foamy histocytes. Patients usually have symptoms of acute cholecystitis in the initial stage. (3) emphysematous cholecystitis, in which air appears in the gallbladder wall due to infection with gas-forming anaerobes, including Clostridium perfringens. This form is likely to progress to sepsis and gangrenous cholecystitis; it is often seen in diabetic patients. (4) Torsion of the gallbladder. ${ }^{69}$ Torsion of the gallbladder is known to occur by inherent, acquired, and other physical causes. An inherent factor is a floating gallbladder, which is very mobile because the gallbladder and cystic ducts are connected with the liver by a fused ligament. Acquired factors in- 
clude splanchnoptosis, senile humpback, scoliosis, and weight loss. Physical factors causing torsion of the gallbladder include sudden changes of intraperitoneal pressure, sudden changes of body position, a pendulum-like movement in the anteflexion position, hyperperistalsis of organs near the gallbladder, defecation, and trauma to the abdomen.

\section{Incidence of complications with advanced forms of acute cholecystitis}

The incidence of complications with advanced forms of acute cholecystitis ranges widely, from $7.2 \%$ to $26 \%$, in reports published since $1990 .{ }^{70-74}$ In patients with acute cholecystitis $(n=368)$, the incidence of morbidity was $17 \%$, with the incidences of gangrenous, suppurative, perforating, and emphysematous cholecystitis being $7.1 \%, 6.3 \%, 3.3 \%$, and $0.5 \%$, respectively. ${ }^{74}$

Types of complications. There are four types of complications. (1) Perforation of the gallbladder, which is caused by acute cholecystitis, injury, or tumors, and occurs most often as a result of ischemia and necrosis of the gallbladder wall. (2) Biliary peritonitis, which occurs with the entry into the peritoneal cavity of bile leaked due to various causes, including cholecystitis-induced gallbladder perforation, trauma, a catheter detached during biliary drainage, and incomplete suture after biliary operation. (3) Pericholecystic abscess, a morbid condition in which a perforation of the gallbladder wall is covered by the surrounding tissue, with the formation of an abscess around the gallbladder. (4) Biliary fistula, which can occur between the gallbladder and the duodenum following an episode of acute cholecystitis. The fistula is usually caused by a large gallbladder stone eroding through the wall of the gallbladder into the duodenum. If the stone is large, the patient can develop gallstone ileus, with the stone causing mechanical smallbowel obstruction at the ileocecal valve.

\section{Prognosis}

The mortality in patients with acute cholecystitis is $0-10 \%{ }^{75-81}$ (Table 8 ), whereas the mortality in patients with postoperative cholecystitis and acalculous cholecystitis is as high as $23 \%-40 \%{ }^{82-84}$ The mortality of elderly patients ( 75 years and older) tends to be higher than that of younger patients, ${ }^{85,86}$ and a comorbidity such as diabetes may increase the risk of death. ${ }^{75}$ Many reports of the mortality and morbidity of acute cholecystitis are difficult to compare, because there are significant variations in the diagnostic criteria, timing and type of operation, presence of comorbidities, and hospital support systems for critically ill patients, as well as variations in available surgical expertise.

According to reports published in 1980 and before, most of the causes of death after cholecystectomy were related to postoperative infections, such as ascending cholangitis, hepatic abscess, and sepsis. ${ }^{76,77}$ Since 1980, postoperative mortality from infection has decreased and the major causes of death include myocardial infarction, cardiac failure, and pulmonary infarction..$^{78,79}$ Cholecystostomy was a common form of treatment in 1970 and before, and the most common cause of death during that period was pneumonia and sepsis. ${ }^{87}$ Currently, the major causes of death following cholecystostomy include malignant tumor, respiratory failure, and cardiac failure. ${ }^{88,89}$

\section{Recurrence rate of acute cholecystitis after conservative treatment}

Most patients with acute cholecystitis are treated with a cholecystectomy, and it is difficult to anticipate whether the outcome will show recurrence. Recurrences of clinical concern include the recurrence of (1) acute cholecystitis after spontaneous recovery without the undergoing of any treatment; (2) acute cholecystitis while waiting for cholecystectomy after conservative treatment with diet modification and antibiotics; (3) acute

Table 8. Mortality of acute cholecystitis

\begin{tabular}{|c|c|c|c|c|c|}
\hline Author & Period & Country & Subjects & No. of cases & Mortality (\%) \\
\hline Meyer $^{76}$ & 1958-1964 & USA & & 245 & 4.49 \\
\hline Ranasohoff $^{75}$ & 1960-1981 & USA & & 298 & 3.36 \\
\hline Gagic $^{77}$ & 1966-1971 & USA & & 93 & 9.68 \\
\hline Girard and Moria ${ }^{78}$ & 1970-1986 & Canada & & 1691 & 0.65 \\
\hline Addison and Finan ${ }^{79}$ & 1971-1990 & UK & & 236 & 4.66 \\
\hline Bedirli $^{80}$ & 1991-1994 & Turkey & & 368 & 2.72 \\
\hline Gharaibeh $^{81}$ & 1993-1900 & Jordan & & 204 & 0 \\
\hline Hafif $^{85}$ & 1952-1967 & Israel & Age, 70 years and older & 131 & 3.82 \\
\hline Gingrich $^{87}$ & 1976-1985 & USA & Only external biliary drainage & 114 & 32 \\
\hline Glenn $^{86}$ & 1977-1987 & USA & Age, 65 years old and older & 655 & 9.92 \\
\hline Kalliafas $^{82}$ & 1981-1987 & USA & Acalculous cases only & 27 & 40.74 \\
\hline Inoue and Mishima ${ }^{83}$ & 1989-1993 & Japan & Postoperative cases only & 494 & 23.08 \\
\hline Savoca ${ }^{84}$ & 1994-1999 & USA & Acalculous cases only & 47 & 6.38 \\
\hline
\end{tabular}


cholecystitis when cholecystectomy is not performed for some reason, such as surgical risk or the patient's decision (with or without biliary drainage); and (4) cholangitis after cholecystectomy.

There are no data on the recurrence of acute cholecystitis after resolution of the initial symptoms. The recurrence of acute cholecystitis while patients are waiting for cholecystectomy following conservative treatment ranges from $2.5 \%$ to $22 \% .{ }^{75,90}$ In 311 patients with acute calculous cholecystitis, 25 of 39 patients who did not have a cholecystectomy during the acute stage were scheduled to undergo delayed operation after being discharged from hospital. Only 1 of the 25 patients $(2.5 \%)$ developed recurrent acute cholecystitis while waiting for an operation. ${ }^{75}$ In non-severe cases, acute cholecystitis recurred in $2 \%$ of patients within an 8 - to 10 -week waiting period, $6 \%$ of whom showed gallbladder perforation..$^{90}$

Long-term recurrence is reported to be $10 \%-50 \%$ in 6 months to several years of observation, though there are few reports. According to a randomized controlled trial comparing non-operative treatment and cholecystectomy for patients with acute cholecystitis, excluding those with severe cases $(n=56), 11 \%$ had a history of acute cholecystitis, and 8 (24\%) of 33 patients assigned to non-operative treatment underwent cholecystectomy during an observation period of $1.5-4$ years. ${ }^{91}$ In patients with acute cholecystitis who were observed after treatment with percutaneous drainage, acute cholecystitis recurred once or more in 28 of 60 patients $(47 \%)$ during an average observation period of 18 months,${ }^{88}$ and it recurred once or more in 11 of $36(31 \%)$ patients who were observed for 37 months on average. ${ }^{89}$ In a report of 114 patients who underwent only cholecystostomy, among 585 patients who were hospitalized because of acute cholecystitis, acute cholecystitis recurred in 5 of 23 patients observed for 6 months to 14 years and 14 of the 23 patients remained asymptomatic. ${ }^{92}$

Acknowledgments. We would like to express our deep gratitude to the Japanese Society for Abdominal Emergency Medicine, the Japan Biliary Association, and the Japanese Society of Hepato-Biliary-Pancreatic Surgery, who provided us with great support and guidance in the preparation of the Guidelines. This process was conducted as part of the project for the Preparation and Diffusion of Guidelines for the Management of Acute Cholangitis (H-15-Medicine-30), with a research subsidy for fiscal 2003 and 2004 (Integrated Research Project for Assessing Medical Technology) sponsored by the Japanese Ministry of Health, Labour, and Welfare.

We also truly appreciate the panelists who cooperated with and contributed significantly to the International Consensus Meeting, held on April 1 and 2, 2006.

\section{References}

1. Lai EC, Tam PC, Paterson IA, Ng MM, Fan ST, Choi TK, et al. Emergency surgery for severe acute cholangitis. The high-risk patients. Ann Surg 1990;211:55-9. (level 3b)

2. Charcot M. De la fievre hepatique symptomatique. Comparison avec la fievre uroseptique. Lecons sur les maladies du foie des voies biliares et des reins, Paris: Bourneville et Sevestre; 1877. p. 176-85. (level 4)

3. Reynolds BM, Dargan EL. Acute obstructive cholangitis. A distinct syndrome. Ann Surg 1959;150:299-303. (level 4)

4. Longmire WP. Suppurative cholangitis. In: Hardy JD, editor. Critical surgical illness. New York: Saunders; 1971. p. 397-424. (level 4)

5. Lipsett PA, Pitt HA. Acute cholangitis. Surg Clin North Am 1990;70:1297-312. (level 4)

6. Gigot JF, Leese T, Dereme T, Coutinho J, Castaing D, Bismuth H. Acute cholangitis: multivariate analysis of risk factors. Ann Surg 1989;209:435-8. (level 4)

7. Saharia PC, Cameron JL. Clinical management of acute cholangitis. Surg Gynecol Obstet 1976;142:369-72. (level 4)

8. Pitt HA, Couse NF. Biliary sepsis and toxic cholangitis. In: Moody FG, Carey LC, editors. Surgical treatment of digestive diseases. ed 2. Chicago: Year Book Medical; 1990. p. 332. (level 4)

9. Thompson JE Jr, Pitt HA, Doty JE, Coleman J, Irving C. Broad spectrum penicillin as an adequate therapy for acute cholangitis. Surg Gynecol Obstet 1990;171:275-82. (level 4)

10. Basoli A, Schietroma M, De Santis A, Colella A, Fiocca F, Speranza V. Acute cholangitis: diagnostic and therapeutic problems. Ital J Surg Sci 1986;16:261-7. (level 4)

11. Daida A, Miki M, Yoshioka M, Moriyama Y. Collective study results on the bacteriological examination during biliary surgery (in Japanese). Jpn J Gastroenterol Surg 1980;13:445-9. (level 4)

12. Edlund YA, Mollsted BO, Ougchterlony O. Bacteriological investigation of the biliary system and liver in biliary tract disease correlated to clinical data and microstructure of the gallbladder and liver. Acta Chir Scand 1959;116:461-76. (level 4)

13. Keighley MR, Lister DM, Jacobs SI, Giles GR. Hazards of surgical treatment due to microorganisms in the bile. Surgery 1974;75:578-83. (level 4)

14. Sinanan MN. Acute cholangitis. Infect Dis Clin North Am 1992;6:571-99. (level 4)

15. Vandervoort J, Soetikno RM, Tham TC, Wong RC, Ferrari AP $\mathrm{Jr}$, Montes H, et al. Risk factors for complications after performance of ERCP. Gastrointest Endosc 2002;56:652-6. (level 4)

16. Freeman ML, Nelson DB, Sherman S, Haber GB, Herman ME, Dorsher PJ, et al. Complications of endoscopic biliary sphincterotomy. N Engl J Med 1996;335:909-18. (level 1b)

17. Lenriot JP, Le Neel JC, Hay JM, Jaeck D, Millat B, Fagniez PL. Catheteisme retrograde et sphincterotomie endoscopique. Evaluation prospective en milieu chirurgical. Gastroenterol Clin Biol 1993;17:244-50. (level 4)

18. Benchimol D, Bernard JL, Mouroux J, Dumas R, Elkaim D, Chazal M, et al. Infectious complications of endoscopic retrograde cholangio-pancreatography managed in a surgical unit. Int Surg 1992;77:270-3. (level 4)

19. Cotton PB, Lehman G, Vennes JA, Geenen JE, Russell RCG, Meyers WC, et al. Endoscopic sphincterotomy complications and their management: an attempt at consensus. Gastrointest Endosc 1991;37:255-8. (level 4)

20. Reiertsen O, Skjoto J, Jacobsen CD, Rosseland AR. Complications of fiberoptic gastrointestinal endoscopy; 5 years' experience in a central hospital. Endoscopy 1987;19:1-6. (level 4)

21. Roszler MH, Campbell WL. Post-ERCP pancreatitis: association with urographic visualization during ERCP. Radiology 1985; 157:595-8. (level 4)

22. Escourrou J, Cordova JA, Lazorthes F, Frexinos J, Ribet A. Early and late complications after endoscopic sphincterotomy for 
biliary lithiasis with and without the gall bladder "in situ". Gut 1984;25:598-602. (level 4)

23. Bilbao MK, Dotter CT, Lee TG, Katon RM. Complications of endoscopic retrograde cholangiopancreatography (ERCP). A study of 10000 cases. Gastroenterology 1976;70:314-20. (level 4)

24. McSherry CK, Ferstenberg H, Virshup M. The Mirizzi syndrome: suggested classification and surgical therapy. Surg Gastroenterol 1982:1:219-25. (level 4)

25. Lemmel G. Die kliniscle Bedeutung der Duodenal Divertikel. Arch Venduungskrht 1934;46:59-70. (level 4)

26. Andrew DJ, Johnson SE. Acute suppurative cholangitis, a medical and surgical emergency. A review of 10 years. Am J Gastroenterol 1970;54:141-54. (level 4)

27. Shimada H, Nakagawara G, Kobayashi M, Tsuchiya S, Kudo T, Morita S. Pathogenesis and clinical features of acute cholangitis accompanied by shock. Jpn J Surg 1984;14:269-77. (level 4)

28. Csendes A, Diaz JC, Burdiles P, Maluenda F, Morales E. Risk factors and classification of acute suppurative cholangitis. Br J Surg 1992;79:655-8. (level 4)

29. Himal HS, Lindsay T. Ascending cholangitis: surgery versus endoscopic or percutaneous drainage. Surgery 1990;108:629-33. (level 4)

30. Chijiiwa K, Kozaki N, Naito T, Kameoka N. Treatment of choice for choledocholithiasis in patients with acute obstructive suppurative cholangitis and liver cirrhosis. Am J Surg 1995;170:356-60. (level 4)

31. Liu TJ. Acute biliary septic shock. HPB Surg 1990;2:177-83. (level 4)

32. Lai EC, Tam PC, Paterson IA, Ng MM, Fan ST, Choi TK, et al. Emergency surgery for severe acute cholangitis. The high risk patients. Ann Surg 1990;211:55-9. (level 4)

33. Thompson JE Jr, Pitt HA, Doty JE, Coleman J, Irving C. Broad spectrum penicillin as an adequate therapy for acute cholangitis. Surg Gynecol Obstet 1990;171:275-82. (level 4)

34. Arima N, Uchiya T, Hishikawa R, Saito M, Matsuo T, Kurisu S, et al. Clinical characteristics of impacted bile duct stone in eldely (in Japanese). Jpn J Geriatr 1993;30:964-8. (level 4)

35. Kunisaki C, Kobayashi S, Kido Y, Imai S, Harada H, Moriwaki $\mathrm{Y}$, et al. Clinical evaluation of acute cholangitis - with speciaal reference to detection of prognostic factor for acute obstructive suppurative cholangitis (in Japanese). J Abd Emerg Med 1997; 17:261-6. (level 4)

36. Tai DI, Shen FH, Liaw YF. Abnormal pre-drainage serum creatinine as a prognostic indicator in acute cholangitis. Hepatogastroenterology 1992;39:47-50. (level 4)

37. Thompson J, Bennion RS, Pitt HA. An analysis of infectious failures in acute cholangitis. HPB Surg 1994;8:139-45. (level 4)

38. Eskelinen M, Ikonen J, Lipponen P. Diagnostic approaches in acute cholecystitis; a prospective study of 1333 patients with acute abdominal pain. Theor Surg 1993;8:15-20.

39. Brewer BJ, Golden GT, Hitch DC, Rudolf LE, Wangensteen SL. Abdominal pain. An analysis of 1000 consecutive cases in a University Hospital emergency room. Am J Surg 1976;131:219-23.

40. Telfer S, Fenyo G, Holt PR, de Dombal FT. Acute abdominal pain in patients over 50 years of age. Scand $\mathrm{J}$ Gastroenterol 1988;144:S47-50.

41. Gouma DJ, Obertop H. Acute calculous cholecystitis. What is new in diagnosis and therapy? HPB Surg 1992;6:69-78. (level 4)

42. Mack E. Role of surgery in the management of gallstones. Semin Liver Dis 1990;10:222-31. (level 4)

43. Hermann RE. Surgery for acute and chronic cholecystitis. Surg Clin North Am 1990;70:1263-75. (level 4)

44. Sharp KW. Acute cholecystitis. Surg Clin North Am 1988;68:26979. (level 4)

45. Williamson RC. Acalculous disease of the gall bladder. Gut 1988;29:860-72. (level 4)

46. Barie PS, Fischer E. Acute acalculous cholecystitis. J Am Coll Surg 1995;180:232-44. (level 4)
47. Reiss R, Deutsch AA. State of the art in the diagnosis and management of acute cholecystitis. Dig Dis 1993;11:55-64. (level 4)

48. Friedman GD. Natural history of asymptomatic and symptomatic gallstones. Am J Surg 1993;165:399-404. (level 2c)

49. Persson GE. Expectant management of patients with gallbladder stones diagnosed at planned investigation. A prospective 5- to 7-year follow-up study of 153 patients. Scand J Gastroenterol 1996;31:191-9. (level 4)

50. Glambek I, Arnesjo B, Soreide O. Correlation between gallstones and abdominal symptoms in a random population. Results from a screening study. Scand J Gastroenterol 1989;24:277-81. (level 2b)

51. Cello JP. AIDS-Related biliary tract disease. Gastrointest Endosc Clin North Am 1998;8:963. (level 4)

52. LaRaja RD, Rothenberg RE, Odom JW, Mueller SC. The incidence of intra-abdominal surgery in acquired immunodeficiency syndrome: a statistical review of 904 patients. Surgery 1989; 105:175-9. (level 4)

53. Michielsen PP, Fierens H, Van Maercke YM. Drug-induced gallbladder disease. Incidence, aetiology and management. Drug Saf 1992;7:32-45. (level 4)

54. Royal College of General Practitioners' oral contraception study. Oral contraceptives and gallbladder disease. Lancet 1982;II:9579. (level 3b)

55. Cooper J, Geizerova H, Oliver MF. Clofibrate and gallstones. Lancet 1975;I:1083. (level 2c)

56. Rosenberg L, Shapiro S, Slone D, Kaufman DW, Miettinen OS, Stolley PD. Thiazides and acute cholecystitis. N Engl J Med 1980;303:546-8. (level 3b)

57. Porter JB, Jick H, Dinan BJ. Acute cholecystitis and thiazides. N Engl J Med 1981;304:954-5. (level 3b)

58. Nelson HD, Humphrey LL, Nygren P, Teutsch SM, Allan JD. Postmenopausal hormone replacement therapy: scientific review. JAMA 2002;288:872-81. (level 1a)

59. Khuroo MS. Ascariasis. Gastroenterol Clin North Am 1996; 25:553-77. (level 4)

60. Sharp HT. The acute abdomen during pregnancy. Clin Obstet Gynecol 2002;45:405-13. (level 4)

61. Barone JE, Bears S, Chen S, Tsai J, Russell JC. Outcome study of cholecystectomy during pregnancy. Am J Surg 1999;177:232-6. (level 2c)

62. Friedman GD, Kannel WB, Dawber TR. The epidemiology of gallbladder disease: observations in the Framingham Study. J Chronic Dis 1966;19:273-92. (level 1b)

63. Gutman H, Sternberg A, Deutsch AA, Haddad M, Reiss R. Age profiles of benign gallbladder disease in 2000 patients. Int Surg 1987;72:30-3. (level 4)

64. Erlinger S. Gallstones in obesity and weight loss. Eur J Gastroenterol Hepatol 2000;12:1347-52. (level 4)

65. Liddle RA, Goldstein RB, Saxton J. Gallstone formation during weight-reduction dieting. Arch Intern Med 1989;149:1750-3. (level 2b)

66. Everhart JE. Contributions of obesity and weight loss to gallstone disease. Ann Intern Med 1993;119:1029-35. (level 2a)

67. Mun EC, Blackburn GL, Matthews JB. Current status of medical and surgical therapy for obesity. Gastroenterol 2001;120:669-81. (level 4)

68. Torgerson JS, Lindroos AK, Naslund I, Peltonen M. Gallstones, gallbladder disease, and pancreatitis: cross-sectional and 2-year data from the Swedish Obese Subjects (SOS) and SOS reference studies. Am J Gastroenterol 2003;98:1032-41. (level 2b)

69. Gross RE. Congenital anomalies of the gallbladder. Arch Surg 1936;32:131-62. (level 4)

70. Hunt DR, Chu FC. Gangrenous cholecystitis in the laparoscopic era. Aust N Z J Surg 2000;70:428-30. (level 4)

71. Merriam LT, Kanaan SA, Dawes LG, Angelos P, Prystowsky JB, Rege RV, et al. Gangrenous cholecystitis: analysis of risk factors and experience with laparoscopic cholecystectomy. Surgery 1999; 126:680-5. (level 4) 
72. Wilson AK, Kozol RA, Salwen WA, Ma LJ, Tennenberg SD. Gangrenous cholecystitis in an urban VA hospital. J Surg Res 1994;56:402-4. (level 4)

73. Bedirli A, Sakrak O, Sozuer EM, Kerek M, Guler I. Factors effecting the complications in the natural history of acute cholecystitis. Hepatogastroenterology 2001;48:1275-8. (level 3b)

74. Tokunaga $Y$, Nakayama N, Ishikawa $Y$, Nishitai R, Irie A, Kaganoi J, et al. Surgical risks of acute cholecystitis in elderly. Hepatogastroenterology 1997;44:671-6. (level 2c)

75. Ransohoff DF, Miller GL, Forsythe SB, Hermann RE. Outcome of acute cholecystitis in patients with diabetes mellitus. Ann Intern Med 1987;106:829-32. (level 2b)

76. Meyer KA, Capos NJ, Mittelpunkt AI. Personal experiences with 1261 cases of acute and chronic cholecystitis and cholelithiasis. Surgery 1967;61:661-8. (level 4)

77. Gagic N, Frey CF, Galness R. Acute cholecystitis. Surg Gynecol Obstet 1975;140:868-74. (level 4)

78. Girard RM, Morin M. Open cholecystectomy: its morbidity and mortality as a reference standard. Can J Surg 1993;36:75-80. (level 4)

79. Addison NV, Finan PJ. Urgent and early cholecystectomy for acute gallbladder disease. Br J Surg 1988;75:141-3. (level 4)

80. Bedirli A, Sakrak O, Sozuer EM, Kerek M, Guler I. Factors effecting the complications in the natural history of acute cholecystitis. Hepatogastroenterol 2001;48:1275-8 (level 4)

81. Gharaibeh KI, Qasaimeh GR, Al-Heiss H, Ammari F, Bani-Hani $\mathrm{K}$, Al-Jaberi TM, et al. Effects of timing of surgery, type of inflammation, and sex on outcome of laparoscopic cholecystectomy for acute cholecystitis. J Laparoendosc Adv Surg Tech 2002;12:193-8. (level 4)

82. Kalliafas S, Ziegler DW, Flancbaum L, Choban PS. Acute acalculous cholecystitis: incidence, risk factors, diagnosis, and outcome. Am Surgeon 1998;64:471-5. (level 4)
83. Inoue T, Mishima Y. Postoperative acute cholecystitis: a collective review of 494 cases in Japan. Jpn J Surg 1988;18:35-42. (level 4)

84. Savoca PE, Longo WE, Zucker KA, McMillen MM, Modlin IM. The increasing prevalence of acalculous cholecystitis in outpatients. Results of a 7-year study. Ann Surg 1990;211:433-7. (level 4)

85. Hafif A, Gutman M, Kaplan O, Winkler E, Rozin RR, Skornick Y. The management of acute cholecystitis in elderly patients. Am Surgeon 1991;57:648-52. (level 4)

86. Glenn F. Surgical management of acute cholecystitis in patients 65 years of age and older. Ann Surg 1981;193:56-9. (level 4)

87. Gingrich RA, Awe WC, Boyden AM, Peterson CG. Cholecystectomy in acute cholecystitis. Factors influencing morbidity and mortality. Am J Surg 1968;116:310-5. (level 4)

88. Andren-Sandberg A, Haugsvedt T, Larssen TB, Sondenaa K. Complication and late outcome following percutaneous drainage of the gallbladder in acute calculous cholecystitis. Dig Surg 2001;18:393-8. (level 4)

89. Granlund A, Karlson BM, Elvin A, Rasmussen I. Ultrasoundguided percutaneous cholecystectomy in high-risk surgical patients. Langenbecks Arch Surg 2001;386:212-7. (level 4)

90. Lahtinen J, Alhava EM, Aukee S. Acute cholecystitis treated by early and delayed surgery. A controlled clinical trial. Scand J Gastroenterol 1978;13:673-8. (level 2b)

91. Sondenaa K, Nesvik I, Solhaug JH, Soreide O. Randomization to surgery or observation in patients with symptomatic gallbladder stone disease. The problem of evidence-based medicine in clinical practice. Scand J Gastroenterol 1997;32:611-6. (level 2b)

92. McLoughlin RF, Patterson EJ, Mathieson JR, Cooperberg PL, MacFarlane JK. Radiologically guided percutaneous cholecystectomy for acute cholecystitis: long-term outcome in 50 patients. Can Assoc Radiol J 1994;45:455-9. (level 4) 